\title{
Effect of stand-off height on the shear strength of ball grid array solder joints under varying pad sizes
}

\author{
Bamidele T. Ogunsemi ${ }^{1} \cdot$ Peter P. Ikubanni ${ }^{1} \cdot$ Adeolu A. Adediran $^{1} \cdot$ Olayinka O. Agboola ${ }^{1}$
}

(c) Springer Nature Switzerland AG 2018

\begin{abstract}
The solder joints of ball grid array utilized in consumer electronics systems or assemblies degrade and fail overtime. Their degree of degradation is more critical, especially at elevated temperatures and mechanical loading conditions. This study presents the effect of component standoff height (CSH) on the shear strength reliability of ball grid array solder joints under different pad sizes. Investigation of the impact of stand off height on the mechanical reliability of the solder joint of ball grid array components under different pad sizes was conducted in this work. Isothermal ageing of test samples were conducted at $150^{\circ} \mathrm{C}$ for 8 days. This study focuses on establishing the relationship between CSH and shear strength of the solder joints under different pad sizes and the corresponding effect of prolonged elevated temperature conditions on the mechanical integrity of the soldered joints. The work also identifies the failure mode and examines the region of the failed joints and surfaces to provide information on the morphological characteristics of the material microstructure. The results of this study demonstrate that the smallest pad size $(19 \mathrm{mil})$ gave the lowest shear strength of $61.08 \mathrm{MPa}$ with a high standoff height of $0.25 \mathrm{~mm}$ as compared to the largest pad size (24 mil) with the highest shear strength of $70.43 \mathrm{MPa}$ having a relatively low standoff height of $0.22 \mathrm{~mm}$.
\end{abstract}

Keywords Stand-off height · Ball grid array · Solder joint · Shear strength · Pad sizes

\section{Introduction}

As consumers' demand for portable devices increase, coupled with the growing trends towards larger packages, use of leadless area array packages and increasing power dissipation, there has been advancement in micro or nano fabrication techniques and surface mount technology in the electronic industry. Also, as a result of the continuous demand for product miniaturization and new applications in portable electronics that are always subjected to human awkwardness, solder joint failure in ball grid array (BGA) packages under shock or drop and high temperature operating conditions has generated a critical reliability issue which has led to various research works and findings in electronics assembly and packaging. The reliability of solder ball interconnects is dependent on the solder material and the intermetallic compound (IMC) morphology formed between the solder and the pad to component metallization. Interconnections are formed in a surface-mount electronic assembly by attaching component terminals having a solder material onto a printed circuit board (PCB). This form of attachment process often involves the chemical interaction of metallurgies from the component terminals, solder ball composition and surface finishes on the base metal of the printed circuit board. Moreover, soldering which forms the most preferred means of attaching surface mount components like the ball grid arrays, diode, transistors, capacitors and other integrated circuits (ICS) to the printed circuit board (PCB) has generated a lot of research concerns on the solder joint reliability in electronic systems. This major concern on solder joint reliability in the electronic packages

Bamidele T. Ogunsemi, obamidele_tope@yahoo.com | 'Department of Mechanical Engineering, Landmark University, P.M.B. 1001, Omu-Aran, Kwara State, Nigeria.

SN Applied Sciences (2019) 1:36 | https://doi.org/10.1007/s42452-018-0044-5 
and assembly, has led to several investigative research works in the electronic manufacturing industry in order to determine the causative factors as well as provide optimal results that address the solder joint reliability issues in electronic assembly $[1,2]$.

In a report presented by $[2,3]$, the design parameters with the greatest impact on BGA assembly reliability are pad diameter, laminate thickness, die size and thickness and solder joint height as there is little effect of solder paste or flux, board finish and the assembly processes. However, solder joint reliability depends on the thermalmechanical behaviour of the solder, the geometry of the solder ball, the material properties of the package, and a higher standoff height of the solder ball which provides better reliability characteristics for an area array package under the same configuration [4]. It was clearly shown in the test results that high standoff solder joint has the highest fatigue lifetime, while low standoff solder joint has the shortest fatigue lifetime. A conclusion was drawn from the experimental results that solder joint crack propagation time is mainly determined by solder joint standoff height $[5,6]$. Basically, the microstructure and composition of solder joints are significantly changed with reducing standoff height $(\mathrm{SOH})$. These changes tend to ultimately affect the mechanical properties and application reliability of solder joints. As the standoff height is reduced, the ultimate tensile strength of the solder joint decreases, with a fracture mode transition from ductile to brittle nature [7]. The effect of standoff height on the microstructure and tensile strength of certain solder joints with given standoff heights has been studied. It was reported that the proportion of IMC thickness to standoff height increases with the decreasing standoff height which will have negative impact on the reliability of solder joints [8]. In a report by [9], results of their studies reveal that the ball grid array (BGA) solder joint reliability increases with the decreasing printed circuit board (PCB) pad size. Their research work also confirmed that increasing the solder joint standoff height can increase the solder joint reliability of the BGA package.

The effects of component standoff-height (CSH) controlled by the relationship between diameter of PCB bond pad and diameter of die bond pad on high-temperature reliability of flip chip lead-free solder joint was conducted by $[1,3,10]$ using finite element method (FEM) tool. It was concluded from the study that the reliability of solder joint in flip chip assembly decreases as CSH decreases, low CSH promotes fatigue cracks at interconnects between IMC at the die side and solder region and that the reliability of solder joints operating at elevated temperatures is dependent on $\mathrm{CSH}$, thickness of IMC and solder volume. Based on this report, the authors are motivated to harness this knowledge to establish the impact of component standoff height (CSH) and board pad sizes on the mechanical integrity of ball grid array (BGA) solder joints. This is to improve the thermo-mechanical reliability of BGA solder joint which are usually subjected to high operating temperatures or thermal cycling. Figure 1 shows a typical solder joint in a BGA assembly.

\section{Methodology}

In this section, the methodology adopted in this work is discussed and presented in details as follows.

\subsection{Materials, components and test vehicle preparation}

The type of surface mount component used for this study is the $9 \times 9$ full array matrix BGA 81 (SAC405 Alloy), with solder ball composition of $95.5 \mathrm{Sn}-3.9 \mathrm{Ag}-0.6 \mathrm{Cu}$ having $0.36 \mathrm{~mm}$ diameter. Other materials include the Universal FR-4 BGA Board (PCB), and the rosin flux. The printed circuit board (PCB) is lead-free and has a tin-plated surface finish with different pad diameters ranging from 19 to 24 mil. The Rosin flux is used to act as a temporary adhesive, holding component in position prior to the reflow soldering process. The BGA components are mounted on the FR-4 PCBs using a pick and place machine, after applying the rosin flux on the PCB to produce the test vehicle. The $\mathrm{CSH}$ s of the various designed test vehicles are achieved by varying the diameter of the pad on the PCB. After the placement of the components (BGAs) by the pick and place machine onto the test boards to form test vehicles, the test vehicles were later transferred into the reflow oven which has been pre-set to solder at a targeted peak temperature of $235^{\circ} \mathrm{C}$. The room temperature and relative humidity during the process were $26.3^{\circ} \mathrm{C}$ and $33 \%$ respectively.

The test vehicles were prepared for metallographic examination by sectioning the solder joints in the

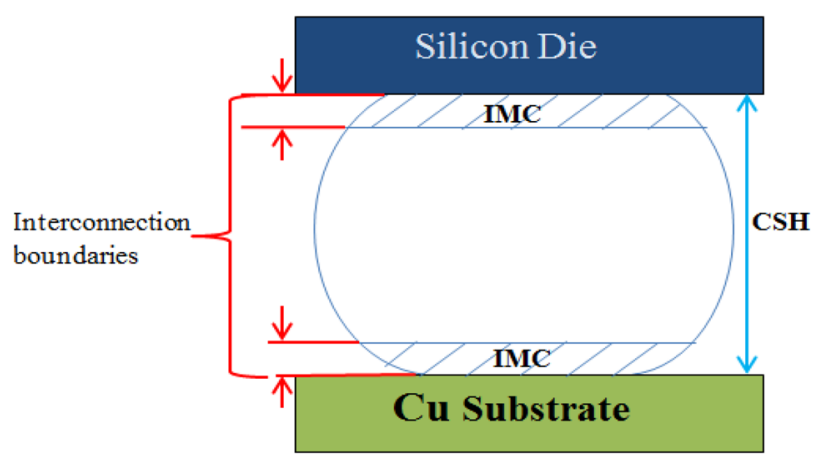

Fig. 1 A BGA bumped soldered joint showing the constituents 


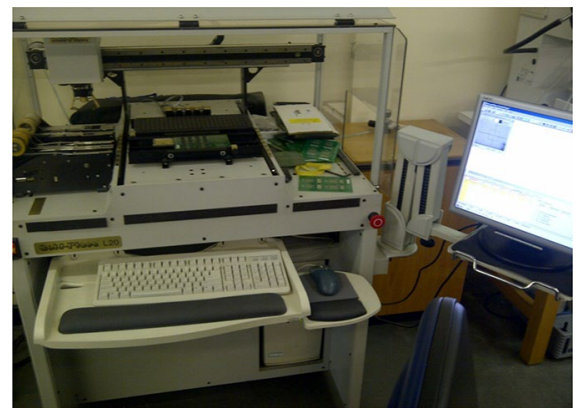

Fig. 2 Pick and place (PnP) machine for component placement
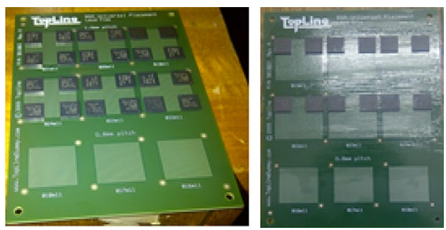

Fig. 3 Test vehicles after components placement

assemblies using Struers Accutom-5 precision cutting machine. The sectioned pieces were moulded using conductive Bakelite powder which allows flow of electron when scanning electron microscope (SEM) is used to take measurements of the CSH. Surface polisher and roll grinder were then used to polish the surfaces of the test vehicles prior to SEM examination.

\subsection{Experimentation processes}

A total number of five (5) PCBs were used, with four (4) components placed on each pad size (i.e. 19 mil, 20 mil, $21 \mathrm{mil}, 22 \mathrm{mil}, 23 \mathrm{mil}$ and 24 mil diameters) to form the shear strength test samples for the as-soldered and aged samples. A computer-controlled pick and place machine was used to place the BGA81 components onto the printed circuit board (PCB) terminations or land areas to form test vehicles temporarily before reflow soldering. Solder flux was initially applied onto the PCB surface to hold the components in position tentatively after being placed by the pick and place machine. Figures 2 and 3 show the images of the pick and place machine and the test vehicles respectively.

\subsection{Reflow soldering process}

Novastar $200 \mathrm{HT}$ Convection Reflow Oven is computercontrolled and was used for the reflow soldering process. After the placement of the components (BGAs) by the pick and place machine onto the test boards to form test vehicles, the test vehicles were later transferred into the reflow oven which has been pre-set to solder at a targeted peak

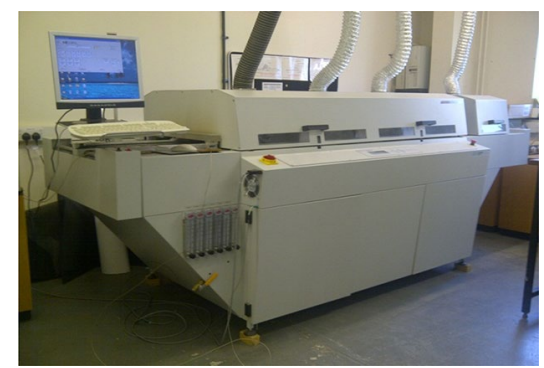

Fig. 4 Novastar 200HT convection reflow oven

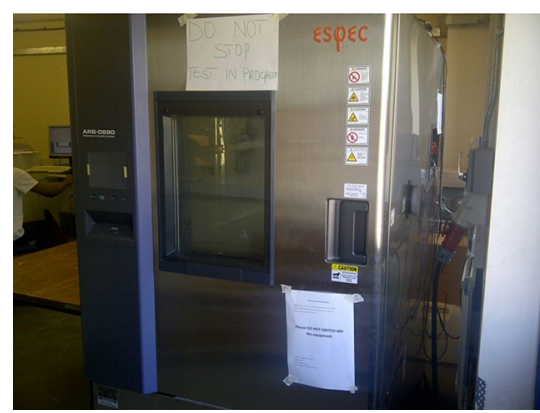

Fig. 5 ESPEC's ARS-0680 environmental chamber

temperature of $235^{\circ} \mathrm{C}$. The room temperature and relative humidity during the process were $26.3^{\circ} \mathrm{C}$ and $33 \%$ respectively. Figure 4 shows the image of the reflow oven adopted for the work.

\subsection{Isothermal ageing process}

ESPEC's ARS-0680 Environmental Chamber was used for this study. This temperature/humidity chamber can withstand heat loads generated by the specimen, improve temperature change rates and also provide expanded ranges for temperature and humidity. Each chamber is also equipped with a specimen temperature control function to meet stringent testing demands typically required for electronic products. The ARS-0680 model specifications are -75 to $180^{\circ} \mathrm{C}$ temperature range and $10-98 \%$ relative humidity range. After the reflow soldering process, the test samples for isothermal aging were placed in the environmental chamber operating at a temperature of $150^{\circ} \mathrm{C}$ and relative humidity of $35 \%$ for 8 days. The chamber was programmed to operate for $200 \mathrm{~h}$. A total of 8 test samples were placed in the chamber (two test vehicles for 8 aging days, both for the shear strength test and SEM examinations). However, as-soldered test samples were produced as standards or bench-marks for each category of the shear strength test and SEM examinations respectively. Figure 5 shows the image of the equipment used for the study. 


\subsection{Shear strength test}

A Multipurpose 4000 Dage Bond Tester was used in this work. The equipment is capable of performing all pull and shear test applications. The Dage bond tester can be configured as a simple wire pull tester which is upgraded to provide ball shear, die shear, and bump pull tests. A total number of five (5) test samples (both the as-soldered and aged samples) were used to carry out the shear strength test, where four (4) BGA81 components were sheared by the machine on the various different pad sizes. Figure 6 shows the Dage bond tester in operation during shear strength test.

\subsection{The precision cutting process}

A precision cutting machine was used to carryout out the cross-sectioning of the various test samples to be used for scanning electron microscopy examination (SEM) of component standoff measurements. This was an attempt to cross-section the BGA81 solder joints or solder bumps for each category of the test samples, both for the as-reflowed and aged samples prior to the metallographic phase of the laboratory work. Figure 7 shows the Precision Cutter in operation during component cross-sectioning.

\subsection{Metallographic preparation of test samples}

This experimental phase involved the production of a conductive mould from a conductive Bakelite powder for mounting of the various test specimens before they are being examined through the scanning electron microscope. The Buehler compression mounting machine was used to produce the mould after a period of about $10 \mathrm{~min}$ of operation. This machine is pneumatically operated or assisted for making moulds for metallurgical test samples prior to electron microscopy investigation. Figure 8 describes the process of mould making on Buehler compression mounting press.

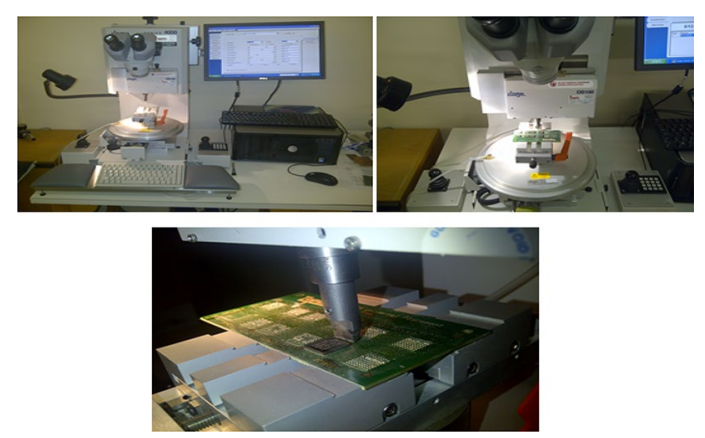

Fig. 6 Dage bond tester in operation during shear strength test

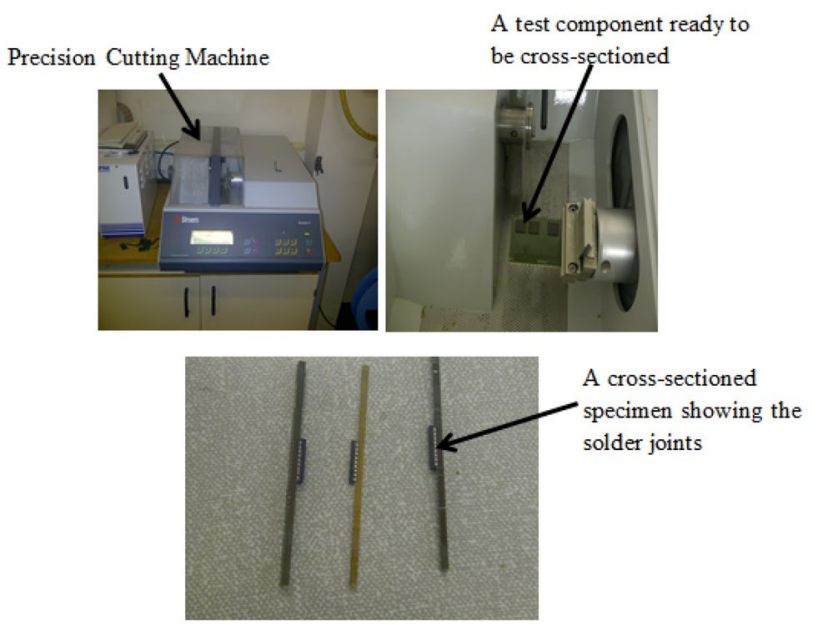

Fig. 7 Precision cutter in operation during component cross-sectioning

\subsection{Scanning electron microscopy}

The JCM-2000 Neoscope was used for this examination. The equipment was used to carry out the component standoff height (CSH) and IMC measurements and also to examine the failure mode of the solder joint. Figure 9 describes the Scanning Electron Microscopy examination of the solder joint.

\section{Results and discussion}

The targeted peak temperature for the reflow soldering of BGA81 test vehicles was $235^{\circ} \mathrm{C}$. A number of four reflow runs were carried out to establish the actual temperatures for the six reflow zones in order to generate this peak temperature. This is done to achieve better repeatability and reproducibility of results before carrying out the actual

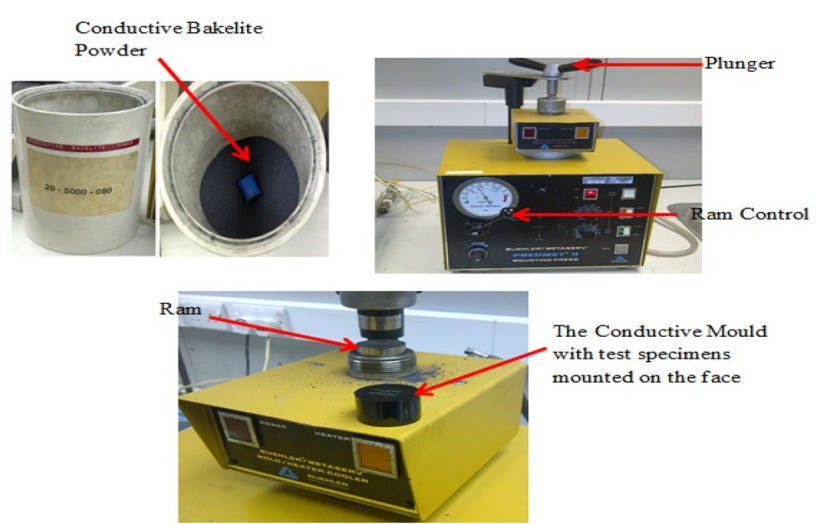

Fig. 8 Buehler compression mounting press in operation

\section{SN Applied Sciences}


Fig. 9 Scanning electron microscopy (SEM) process

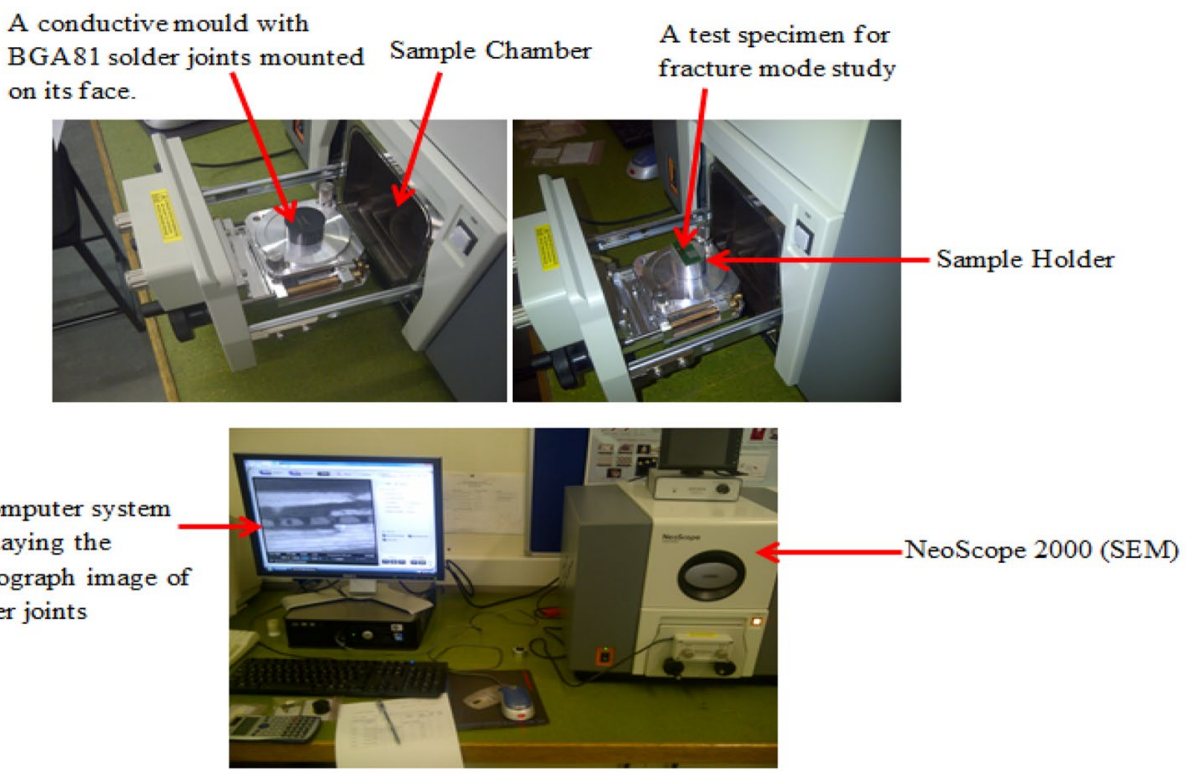

reflow soldering of the test vehicles. The thermal profiles (in this case is a ramp-to-spike profile) produced for the number of reflow runs and actual reflow soldering were generated directly with the aid of a thermocouple connected to the reflow oven while the results are displayed and read through a computer system integrated with the oven. This process was carried out under the same environmental conditions of $26.1^{\circ} \mathrm{C}$ room temperature and relative humidity of $33 \%$. Results for the $235^{\circ} \mathrm{C}$ peak temperature thermal profile used for the actual soldering process is presented in Fig. 10 below.

\subsection{Shear strength analysis}

The shear strength $(\Gamma)$ values were calculated directly by determining the surface area $(A)$ of the entire 81 solder balls and dividing it by the shear force (F) exerted as illustrated below;

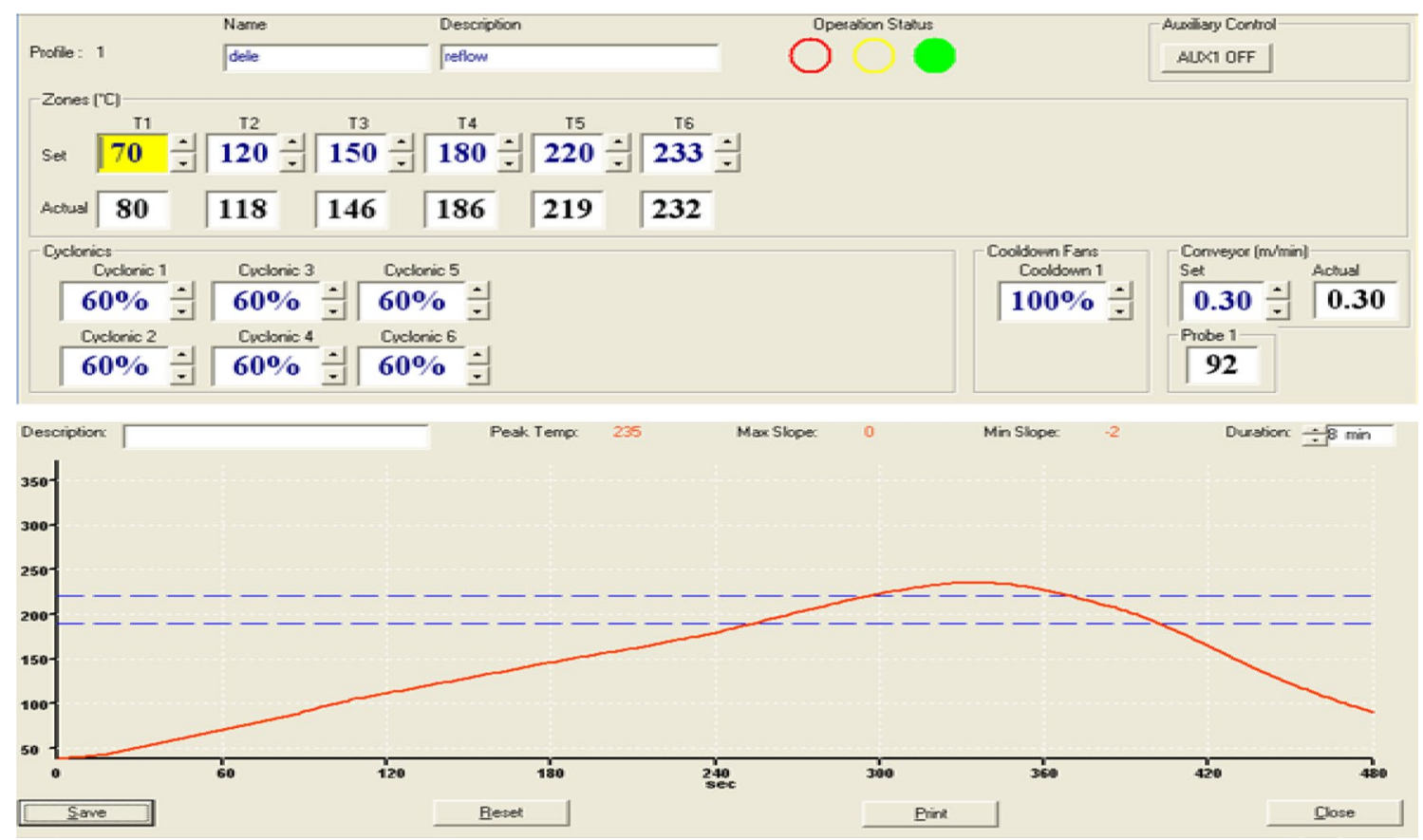

Fig. 10 The reflow profile result for $235^{\circ} \mathrm{C}$ peak temperature soldering 
Assuming the shape of a solder ball is a circle and using the expressions,

Shear strength $(\Gamma)=\frac{\text { Shear Force }(F)}{\text { Surface Area }(A)}$

Cross sectional area $(\mathrm{A})=\frac{\pi D^{2}}{4}\left(\mathrm{~m}^{2}\right)$

The solder ball diameter $=0.36 \mathrm{~mm}=0.00036 \mathrm{~m}$. From Eq. (2) above,

Cross sectional area $(\mathrm{A})=\frac{\pi D^{2}}{4}\left(\mathrm{~m}^{2}\right)$

$\mathrm{A}=\frac{3.142 \times 0.00036^{2}}{4}=\frac{3.142 \times 1.296 \times 10^{-7}}{\times}$

$$
=\frac{4.072 \times 10^{-7}}{4}=1.018 \times 10^{-7} \mathrm{~m}^{2}
$$

The cross sectional area (A) of one solder ball $=1.018 \times 10^{-7} \mathrm{~m}^{2}$ Hence, for 81 solder balls,

Cross sectional area $(A)=\left(1.018 \times 10^{-7} \times 81\right) \mathrm{m}^{2}$

$$
=8.25 \times 10^{-6} \mathrm{~m}^{2}
$$

Thus, the shear area of the BGA81 solder joint is $8.25 \times 10^{-6} \mathrm{~m}^{2}$.

Each of the four components placed on different pad sizes were sheared under the same condition of shear speed and shear height of $200 \mu \mathrm{m} / \mathrm{s}$ and $60 \mu \mathrm{m}$ respectively. The shear strength for the as-reflowed sample is given as;

$$
\begin{aligned}
\text { Shear strength }(\Gamma) & =\frac{\text { Shear Force }(N)}{\text { Surface Area }\left(\mathrm{m}^{2}\right)} \\
& =\frac{539.16(N)}{8.25 \times 10^{-6}} \\
& =65.35 \times 10^{6} \mathrm{~N} / \mathrm{m}^{2} \text { or } 65.35 \mathrm{MPa}
\end{aligned}
$$

This same approach was however taken in calculating the shear strengths for the other test samples.

Table 1 Shear strengths and the CSHs values for as-reflowed test specimen

\begin{tabular}{llll}
\hline S/N & $\begin{array}{l}\text { Pad diameter } \\
\text { (mil) }\end{array}$ & $\begin{array}{l}\text { Average shear } \\
\text { strength (MPa) }\end{array}$ & $\begin{array}{l}\text { Standoff } \\
\text { height (CSH), } \\
\mathrm{mm}\end{array}$ \\
\hline 1 & 19 & 65.35 & 0.26 \\
2 & 20 & 74.22 & 0.26 \\
3 & 21 & 77.45 & 0.23 \\
4 & 22 & 78.32 & 0.24 \\
5 & 23 & 83.58 & 0.25 \\
6 & 24 & 84.79 & 0.20 \\
\hline
\end{tabular}

\subsection{Graphical analysis of the shear strengths with varying pad sizes}

The shear strength results for the as-reflowed and aged test specimens as shown in Tables 1 and 2 were plotted against the different pad sizes in order to further analyse the behavioural relationship between them. The component standoff height (CSH) is a function of the PCB pad sizes that should be taken into consideration when determining its effect on the shear strength of the BGA81 components. The relationship between shear strength of the solder joints and the diameter of pad on the PCB are shown in Figs. 11 and 12 for the as-soldered and 8-days aged test samples respectively, while Figs. 13 and 14 show the relationship between the CSHs and shear strengths for the as-soldered and 8-days aged samples respectively. The plots show that the shear strengths of the joints increases as the pad diameter increases with decreasing $\mathrm{CSH}$. These plots demonstrate that the pad diameter and CSH has significant contribution to the structural reliability of an electronic assembly.

The significance of this finding is that a device assembled using solder joints of components having higher shear strength will possess greater reliability because such

Table 2 Table of shear strengths and CSHs for 8 days aged test specimen

\begin{tabular}{llll}
\hline S/N & $\begin{array}{l}\text { Pad diameter } \\
\text { (mil) }\end{array}$ & $\begin{array}{l}\text { Average shear } \\
\text { strength (MPa) }\end{array}$ & $\begin{array}{l}\text { Standoff } \\
\text { height (CSH), } \\
\mathrm{mm}\end{array}$ \\
\hline 1 & 19 & 61.08 & 0.25 \\
2 & 20 & 61.81 & 0.18 \\
3 & 21 & 65.68 & 0.22 \\
4 & 22 & 66.71 & 0.23 \\
5 & 23 & 68.52 & 0.26 \\
6 & 24 & 70.43 & 0.22 \\
\hline
\end{tabular}

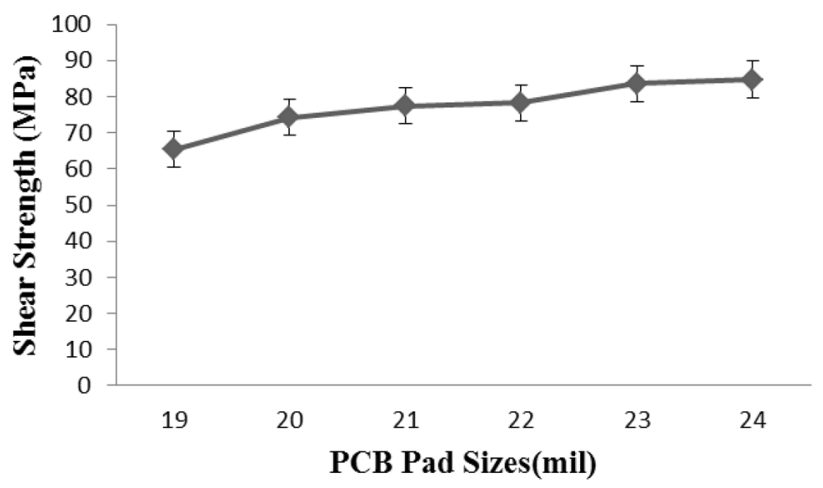

Fig. 11 Shear strength against pad sizes for as-reflowed test samples 


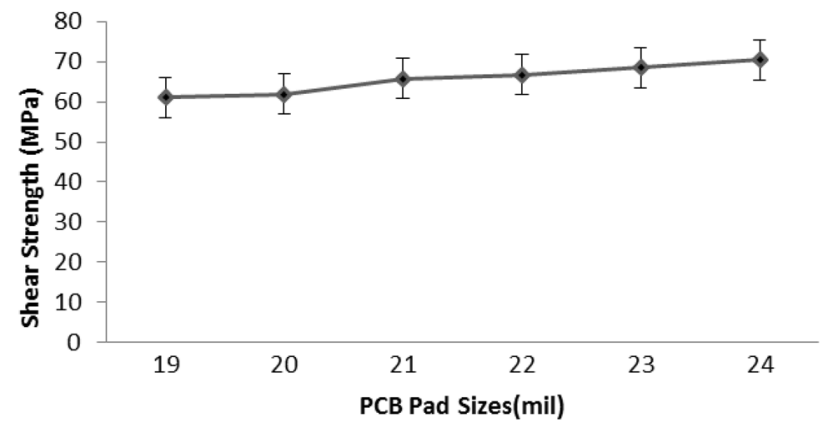

Fig. 12 Shear strength against pad sizes for 8-days aged test sample

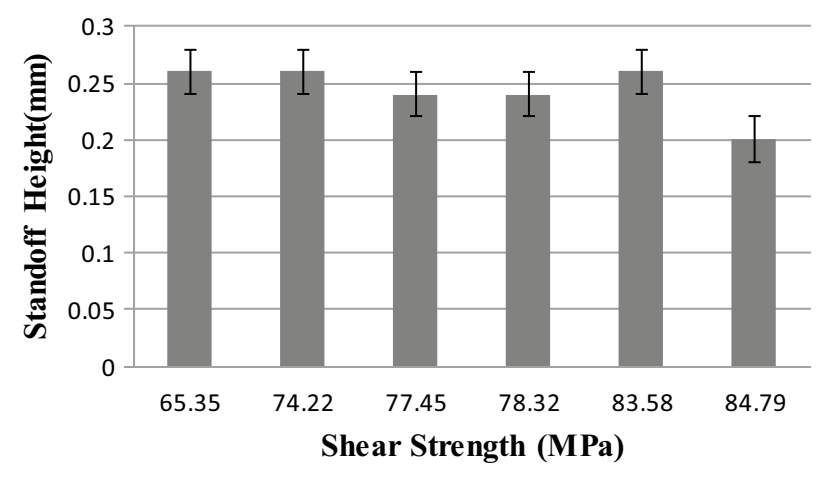

Fig. 13 Standoff height against shear strength for as-reflowed test samples

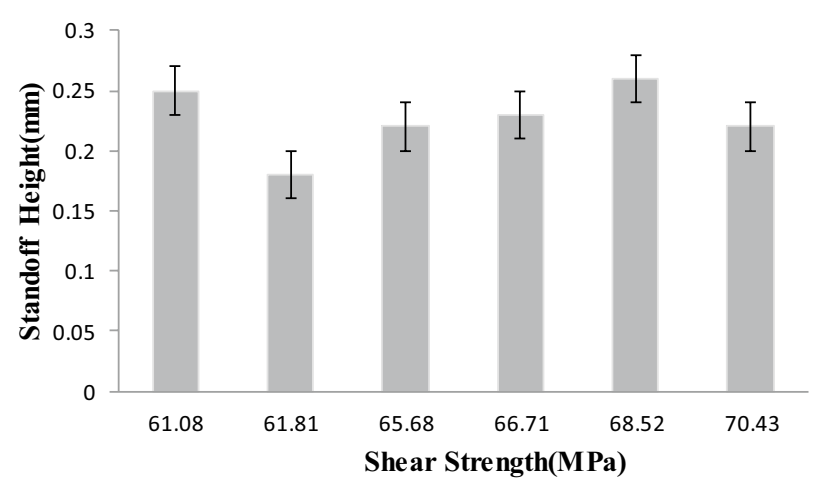

Fig. 14 CSH against shear strength for 8-days aged test sample

joints will withstand high shock load electronic devices experience when dropped from an elevated height.

The mechanical reliability of lead-free bulk solder joint is dependent on the adhesive strength formed between the die pad/solder and solder/substrate pad metallization $[5,7]$. The shear strength of the $9 \times 9$ matrix bulk solder joint (SAC405) for BGA81 component have been obtained through a ball shear test. The shear strength integrity or reliability study was focused on the solder balls of BGA which undergo chemical interactions during soldering and ageing process. It was practically impossible to measure the diameter of already collapsed array of solder balls mounted on a PCB after soldering. However, the collapse of the solder balls during reflow soldering is ideal for effective and efficient joint formation but the mechanical integrity or reliability of the solder joint must be tested and evaluated through a ball shear test for real applications. Hence, the solder ball diameter provided by the product manufacturer was utilized for the shear strength calculation in this study. Experimental results from Tables 1 and 2 show that; the shear strength of the as-reflowed test specimens is higher and provides a stronger solder joint in comparison to the 8-days aged samples. The mechanical strength of the asreflowed samples increases with increasing pad sizes.

At a reflow peak temperature of $235^{\circ} \mathrm{C}$ and as shown in Fig. 11, the as-soldered BGA81 test samples produced stronger and more reliable solder joints with the largest $P C B$ pad size (24 mil); providing the highest shear strength of 84.79 MPa. This is in comparison to the 8 days aged $24 \mathrm{mil}$ pad size sample that produced average shear strength of $70.43 \mathrm{MPa}$ as shown in Fig. 14. The predominant factor responsible for the strength or mechanical reliability of the BGA81 solder joint is the formation or growth of intermetallic compounds (IMC) at the interconnection boundaries between the solder joint and the substrate pad during metallization. This metallization process is an interfacial reaction that occurs between the chemical composition of the solder ball (SAC405) and the tin-plated FR-4 printed circuit board. The interfacial reaction products referred to as IMC, impacts significantly the solder joint reliability in terms of the shear strength.

The relationship between the component standoff height (CSH) and the shear strength for both the asreflowed and 8-days aged test samples are illustrated graphically in Figs. 13 and 14 respectively. The results are also presented on Tables 1 and 2 for both the as-reflowed and 8-days aged test samples respectively. However, the Tables and Figures indicate that the shear strength values for as-reflowed test samples are higher than those of the corresponding 8-days aged test samples with the same pad sizes. The reduced shear strength is due to the formation of brittle intermetallic compound (IMC) formation between the solder ball and the pad substrate after ageing for 8 days. Moreover, the CSH for the 8-days aged samples are expected to be higher than those of the as-reflowed samples due to the growth of the IMC at the interface of connection between the solder balls and the pad substrate. This is clearly revealed by the 23 mils and 24 mils pad diameters for both as-reflowed and aged samples. However, the anomalous relationship given by the graphical representations in Figs. 13 and 14 could be as result of 
misalignment of the component on the PCB terminations by pick and place machine, nature of flux(adhesive) used and other reflow soldering conditions.

The CSH measurements for the as-soldered and aged samples were carried out on a Scanning electron microscope as shown in Figs. 15 and 16 respectively. These images represent the 19 mil and 20 mil pad diameters for the various test samples.

\subsection{SEM images of the BGA81 solder joints revealing the CSHs during scanning electron microscopy (SEM) measurements}

See Figs. 15 and 16.

\subsection{SEM images of the fractured mode of the BGA 81 solder joints for the as-reflowed and aged test samples after shearing}

The modes of failure of the BGA81 solder joints for the as-soldered and aged test specimens have been critically examined. This was carried out under a scanning electron

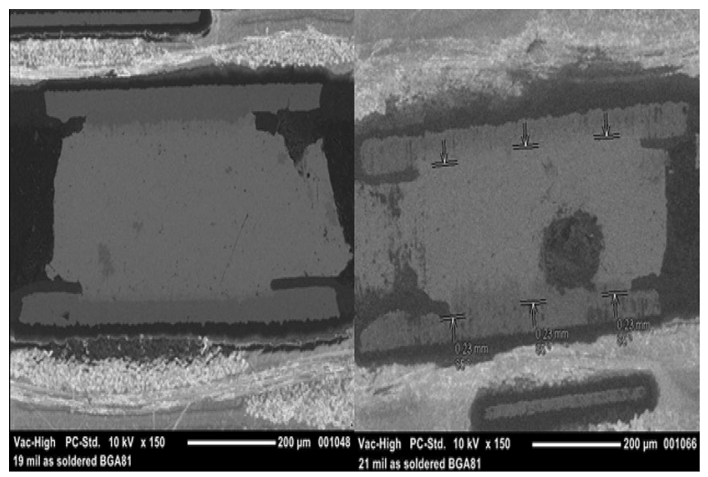

Fig. 15 SEM images of the as-soldered test specimen at showing the CSH measurements for the 19 mil and 20 mil pad sizes respectively

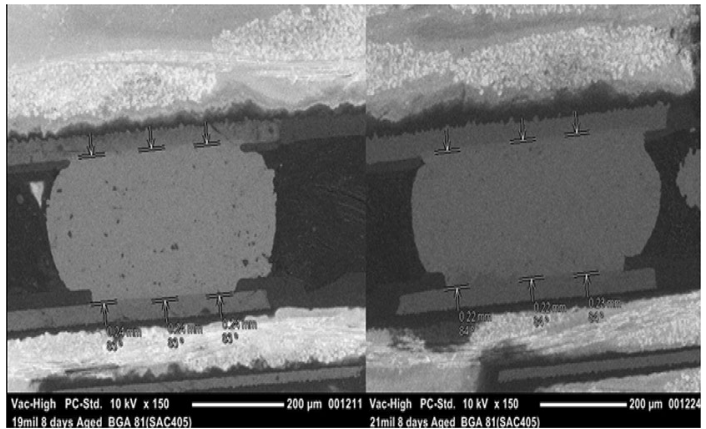

Fig. 16 SEM Images of the 8-days aged test specimen at $150{ }^{\circ} \mathrm{C}$ showing the $\mathrm{CSH}$ measurements for the 19 mil and 20 mil pad sizes respectively microscopy (SEM) and the images are shown in Figs. 17 and 18 for the as-soldered and aged samples respectively. It could be observed from Fig. 17 and 18 that the solder joints from each test sample revealed similar fracture behaviour. This indicates IMC fracture areas with component pad, bulk solder fracture and partial pad lifting or cratering effect [8]. The IMC fracture mode which was basically initiated at the boundary of interconnection of the die pad and solder/IMC interfaces, gives an indication of a brittle failure due to the weak intermetallic formed at the interface [3]. This fracture mode forms the most dominating failure behaviour of the solder joints for both as-soldered and the 8 days aged samples.

In addition to the IMC fracture, failure also occurred within the bulk solder leaving some volume of solder on the substrate pad. This is a typical ductile failure mode also observed in the as-reflowed and 8 days aged test specimen. From observation, the ductile nature of the solder joint increases with aging. The 8-days aged sheared joint showed more ductile fracture as shown in Fig. 18. Partial

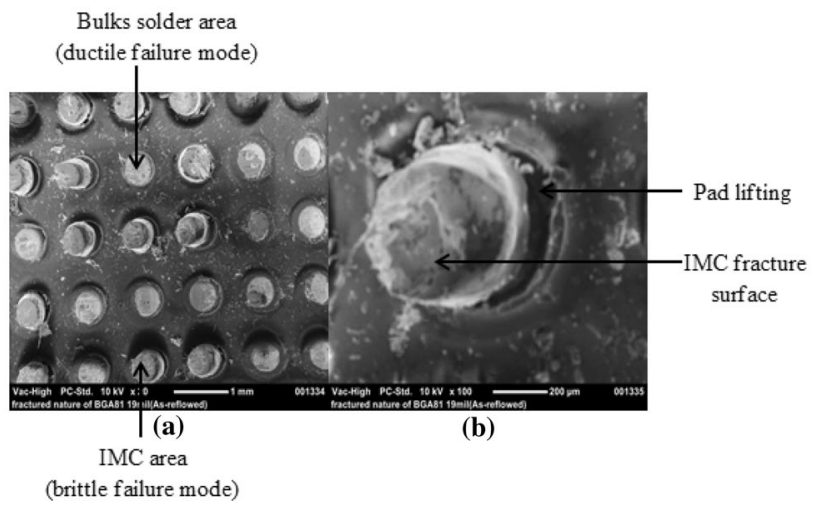

Fig. 17 SEM images for failure mode definition a solder joints area array showing bulk solder fracture and IMC fracture; b solder joint with IMC fracture and pad lifting for as-reflowed 19 mil pad size

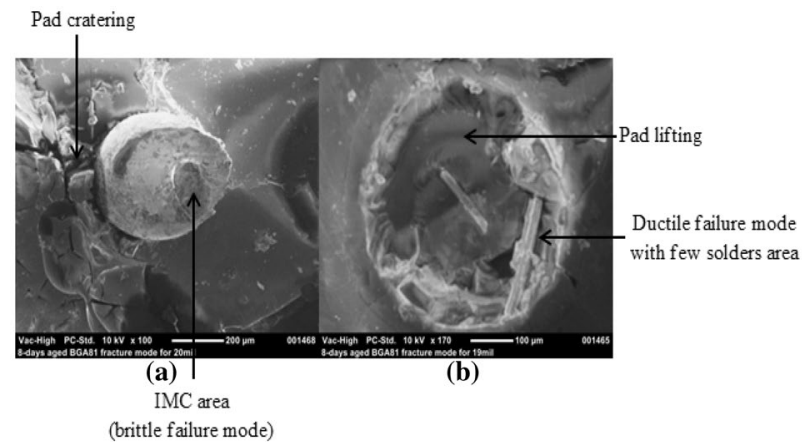

Fig. 18 SEM images for failure mode definition a solder joint fracture mode showing pad cratering and IMC fracture surface; b fractured surface showing pad lifting and ductile failure mode for 8-days aged 19 mil pad size 
pad lifting is another failure mode observed in the solder joints as shown in Fig. 17 for the as-soldered sample. Only the 8-days aged sample showed numerous complete Pads lifting with craters around the PCB substrate pad. The dominant IMC fracture mode between the component pad and IMC/solder interfaces corresponds to the shear strength results as discussed earlier. The brittleness of the intermetallic microstructure decreases with aging, which makes the 8-days aged sample possess more ductile solder joints. Hence, the most critical boundary of interconnection of the BGA81 solder joints is that between the BGA substrate pad and the solder/IMC interfacial connection, where there seemed to be a high level of stress concentration and embrittleness. Moreover, apart from the rate of IMC growth, the solder joint failure can also be attributed to certain factors such as the dissolution of surface finish layers, compositional changes and PCB pad design [9]. The nature of propagation of the solder joint failure during shearing is strongly at the boundary of interconnection of the die pad and solder joint, within the bulk solder and at the interface between the substrate pad and solder joint. This failure mode is similar as observed from the as-reflowed and aged test specimens. The most critical and predominant failure mode characterised by the as-reflowed and aged test specimens is the IMC brittle fracture. The interconnection boundary between the tin-plated FR-4 substrate pad and the bulk solder gave a strong metallurgical bonding or strength that resulted into a ductile fracture mode. The nature of the failed or fractured boundaries includes; IMC fracture, bulk solder fracture and pad lift. The interface between $\mathrm{Cu}_{6} \mathrm{Sn}_{5} \mathrm{IMC}$ and bulk solder becomes the weakest link which corresponds to the nature or mode of the solder joints failure obtained from these research findings.

\section{Conclusion}

The results from the evaluation of the relationship between the pad sizes and the BGA shear strengths showed that; as the pad sizes increases, the solder joint shear strengths also increases. Hence, the solder joint shear strength is dependent on the pad sizes. Evaluation of the results on the impact of pad sizes on the component standoff height indicated that; the smallest (19 mil) and largest ( $24 \mathrm{mil}$ ) pad sizes gave the highest and lowest standoff heights respectively which significantly affects the shear strengths. Therefore, the component standoff heights are functions of the pad sizes.

The $150{ }^{\circ} \mathrm{C}$ isothermal aging of $\mathrm{Sn}-\mathrm{Ag}-\mathrm{Cu}$ solder alloy with tin-plated FR-4 substrate showed that; the growth of IMC is dependent on the aging temperature and time. Hence, the CSH and shear strength of BGA component are significantly influenced by the thicknesses of IMC formed. From the results of $\mathrm{CSH}$ and shear strength, the lowest standoff height (largest pad size) gave the highest shear strength and the highest standoff height (smallest pad size), gave the least shear strength. Thus, the shear strength of BGA solder joint is higher with reduced $\mathrm{CSH}$.

The predominant failure mode exhibited by both the as-reflowed and the various aged specimens after ball shear test is the IMC brittle fracture. Generally, the nature and failure mechanism exhibited by the SAC405 solder joint is in three modes namely; the IMC fracture, bulk solder fracture and pad lift.

At $150{ }^{\circ} \mathrm{C}$ isothermal aging, the $24 \mathrm{mil}$ pad size aged for 8 days gave the highest and optimal shear strength of $70.43 \mathrm{MPa}$, with a CSH of $0.22 \mathrm{~mm}$ as compared to the 24 mil pad size as-soldered sample having shear strength of $84.79 \mathrm{MPa}$ and $\mathrm{CSH}$ of $0.20 \mathrm{~mm}$. Hence, results show that the 8 days aged 24 mil pad size gave the optimum value of shear strength for BGA81 solder joints thereby providing a higher mechanical integrity as compared to the as-soldered sample.

Acknowledgements The authors gratefully acknowledge the contributions of Dr. Sabuj Mallik and the University of Greenwich Electronics Manufacturing Engineering Research Group (EMERG), UK towards the successful completion of this work.

\section{Compliance with ethical standards}

Conflict of interest The authors declare that they have no conflict of interest.

\section{References}

1. Emeka HA, Ekere NN (2012) Prediction of damage and fatigue life of high-temperature flip chip assembly interconnections at operations. Microelectron Reliab 52(11):2731-2743

2. Bernasko PK (2012) Study of intermetallic compound layer formation, growth and evaluation of shear strength of lead-free solder joints. Doctoral thesis, Electronic Manufacturing Engineering Research Group (EMERG), School of Engineering, University of Greenwich, Medway, Kent

3. Du B, Wu F, Wang B, Bing A, Yiping W (2009) Effect of stand-off height on the microstructure and tensile strength of the $\mathrm{Cu} /$ $\mathrm{Sn}-8 \mathrm{Zn}-3 \mathrm{Bi} / \mathrm{Cu}$ and $\mathrm{Cu} / \mathrm{Sn}-9 \mathrm{Zn} / \mathrm{Cu}$ solder joint. In: IEEE Journal of Electronic Component and Technology Conference, pp 1044-1048

4. Glenn R, Blackwell PE, Hollomon JK (2006) Surface-mount technology for PC boards, 2nd ed. Thomson Delmar

5. Clech JM (1996) Solder reliability solutions: from LCCCS to area-array assemblies. In: Proceedings, Nepcon West'96, pp $1665-1680$

6. Njoku JE, Mallik S, Bhatti R, Emeka HA, Ogunsemi B (2015) Effects of component stand-off height on reliability of solder joints in assembled electronic component. In: European microelectronics packaging conference, $\mathrm{pp}$ 1-4 
7. Chang Kuo-Ning, Te Lin Yung-, Cheng Hsien-Chie (2000) On enhancing eutectic solder joint reliability using a secondreflow-process approach. IEEE Trans Adv Packag 23(1):9-14

8. Liu X, Quan Lu G (2003) Effects of solder joint shape and height on the thermal fatigue lifetime. IEEE Trans Compon Packag Technol 26(2):455-465

9. Zhang L, Soon SC, Maheshwari A (2002) Effect of solder ball pad design on cavity down BGA solder joint reliability. In: The 52 nd proceeding of IEEE electronic component and technology conference, pp 1001-1006

10. Njoku JE, Mallik S, Bhatti R, Emeka HA, Ekere NN (2015) Effect of component standoff height on thermo-mechanical reliability of ball grid array (BGA) solder joints operating in high-temperature ambient. In: IEEE transactions-38th international spring seminar on electronics technology, pp 231-236 